\title{
Complications of Stapled Haemorrhoidectomy for Primary Haemorrhoid - Our Experience in ShSMCH
}

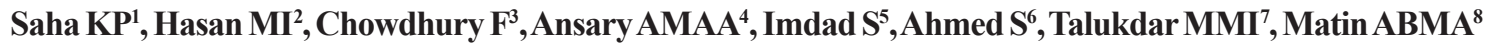

Conflict of Interest: None Received: 22-08-2017

Accepted: $12-11-2017$ www.banglajol.info/index.php/JSSMC

Key Words:

Stapled Haemorrhoidectomy,

Complications of

Haemorrhoidectomy

\begin{abstract}
Objective: The aim of the study was to cheek the rate of significant complications amongst the patients undergoing Stapled haemorrhoidectomy. This study reflects our experience with Stapled haemorrhoidectomy in our Population.
\end{abstract}

Methods: Two hundred and ninety patients with primary hemorrhoid of different degree underwent staple Hemorrhoidectomy in ShSMCH since January 2011 to December 2016. All patients were evaluated by history, clinical examination and proctosigmoidoscopy. They were followed up post operatively at 1, 3, 6, 12, 15, 18 Month.

Result: Regarding presenting symptoms (pain less) per rectal bleeding was the main symptom (89\%). Bulk of the pt were $3^{\text {rd }}$ degree $(50.16 \%)$. Regarding post operative complication Urgency of defecation was most frequent (19\%). Others were Urinary retention (4.5\%), anal pain $(4.01 \%)$, reactionary hemorrhage $(4.01 \%)$. Regarding late post operative complication most frequent was mild pain (3.34\%); others were - flatus incontinence, stenosis, recurrent haemorrhoid, fissure.

Conclusion : Stapled haemorrhaidectomy is widely used, quick, safe and effective method of treating all degree of primary hemorrhoid with some complications. Therefore surgeon should be well aware of the type and post operative complications

[J Shaheed Suhrawardy Med Coll 2017; 9(2): 78-82] DOI: http://dx.doi.org/10.3329/jssmc.v9i2.37268

\section{Introuction:}

Haemorrhoids are a very common anorectal condition defined as the symptomatic enlargement and distal displacement of the normal anal cushions. They affect millions of people around the world, and represent a major medical and socioeconomic problem. ${ }^{1}$

1. Dr. Krishna Pada Saha, Junior Consultant, Department of Surgery, Shaheed Suhrawardy Medical College Hospital

2. Dr. Md. Ibnul Hasan, Registrar, Department of Surgery, Shaheed Suhrawardy Medical College Hospital

3. Dr. Fayem Chowdhury, Registrar, Department of Surgery, Shaheed Suhrawardy Medical College Hospital

4. Dr. Abdullah Md. Abu Ayub Ansary, Resident Surgeon, Shaheed Suhrawardy Medical College Hospital

5. Dr. Sadia Imdad, Resident Surgeon, Shaheed Suhrawardy Medical College Hospital

6. Dr. Sami Ahmad, Associate Professor, Department of Surgery, Shaheed Suhrawardy Medical College Hospital

7. Dr. Md. Monwarul Islam Talukdar, Resident Surgeon, Shaheed Suhrawardy Medical College Hospital

8. Dr. Abul Bashar Md. Abdul Matin, Associate Professor, Department of Surgery, Sheikh Sayera Khatun Medical College, Gopalgonj

Correspondence to: Dr. Krishna Pada Saha, Junior Consultant, Department of Surgery, Shaheed Suhrawardy Medical College Hospital. E-mail: drkpsaha@gmail.com
Haemorrhoids is derived from a Greek word meaning flow of blood (heam- blood rhoos- flowing). The word piles come from latin pila meaning pill or a ball. There are few diseases that are more chronical in human history than symptomatic haemorrhoidal disease. ${ }^{2,3}$ Multiple factors have been claimed to be the etiologies of haemorrhoidal development, including constipation and prolonged straining. The abnormal dilatation and distortion of the vascular channel, together with destructive changes in the supporting connective tissue within the anal cushion, is a paramount finding of haemorrhoidal disease. ${ }^{3}$

It has been traditional to grade haemorrhoidal disease into four degrees depending on the extent of the prolapsed. After the haemorrhoids are appropriately staged, treatment options should be explored. Although this grading system has limitations, it is beneficial to determine the efficacy of various forms of treatment. ${ }^{4}$

In most instances, haemorrhoids are treated conservatively, using many methods such as lifestyle 
modification, fiber supplement, suppository-delivered antiinflammatory drugs, and administration of venotonic drugs. ${ }^{5}$ Non-operative approaches include sclerotherapy and, preferably, rubber band ligation. An operation is indicated when non-operative approaches have failed or complications have occurred.

Several surgical approaches for treating haemorrhoids have been introduced including haemorrhoidectomy and stapled haemorrhoidopexy.

Stapled Haemorrhoidopexy (SH) was first described by an Italian surgeon, Dr. Antonio Longo, Department of Surgery, University of Palermo, in late 1990 's ${ }^{6}$ and since then has been widely adopted worldwide. This operation involves the use of a stapled gun inserted through the anus to hold back the internal haemorrhoids and re-duce the degree of prolapse by excising a circumferential strip of mucosa from the proximal anal canal. Stapled haemorrhoidopexy is usually reserved for $3 \mathrm{rd}$ and 4 th degree haemorrhoids. It is sometimes used to treat 2 nd degree haemorrhoids as well. It gives minimal pain after the operation and earlier return to work or normal activity, compared to open haemorrhoidectomy. It does not need to be performed in stages and there is no external wound. Apart from a few isolated severe complications like pelvic abscess and severe bleeding ${ }^{7}$, the complication rates of $\mathrm{SH}$ are comparable to other conventional haemorrhoid $(\mathrm{CH})$ operations ${ }^{8-10}$. A large multicentre study in Italy showed a complication rate of $15 \%$. The commonest complications were severe pain and bleeding, at $5 \%$ and $4 \%$ respectively.

Pain is the most frequent complication and the most feared sequel of the procedure from the patient's perspective. ${ }^{11}$

Urinary retention is a frequent postoperative problem after haemorrhoidectomy, ranging in incidence from 1 to $52 \% .{ }^{12}$, 13

Early postoperative bleeding ( $<24$ hours) occurs in approximately $1 \%$ of patients and represents a technical error that requires return to the operating room for resuturing of the offending wound. ${ }^{14}$ Delayed hemorrhage occurs in 0.5 to $4 \%$ of cases of excisional haemorrhoidectomy at 5 to 10 days postoperatively. ${ }^{15}$

Anal stenosis - provided adequate mucosal bridges are retained after excision ligation of haemorrhoids this complication should be rare. Anal fissures is a rare complication which may result from a failure of the haemorrhoidectomy site to heal adequately Skin tagsedema in the perianal skin adjacent hemorrhoid wounds may result in skin tags. The incidence of skin tags is reported to occur in $4 \%$ of patients after excision ligation.

\section{Materials and Methods:}

This is a prospective observational study, conducted over a period between January 2011 to December 2016 carried out in Shaheed Suhrawardy Medical College Hospital. Two hundred and ninty nine consecutive patients with idiopathic/primary haemorrhoidal disease irrespective of age, sex, height, nutritional conditions, and socioeconomic status were selected for the procedure. Patients with asymptomatic secondary haemorrhoids or with other associated benign anorectal disorders were excluded from the study. Diagnosis of haemorrhoidal disease was made form history, and examination of anorectal by conventional digital rectal examination and proctosigmoidoscopic examination. Relevant investigations were done for anesthetic fitness.

\section{Technique}

Staple Haemorrhoidectomy was carried out under spinal anesthesia, with the patient in lithotomic position. After gentle dilation of the anus the purse-string anuscope was introduced into the anal canal. A circumferential pursestring suture was placed approximately $2-3 \mathrm{~cm}$ above the dentate line with $3 / 0$ vicryl, taking care that only the mucosa and submucous layers are incorporated the pursestring suture. The PPH03 haemorrhoidal circular stapler is opened fully and the $33 \mathrm{~mm}$ anvil is introduced into the anal canal. It is positioned above (proximal to) the pursestring, which is then tied down. The suture threader is then used to pull the suture though the lateral holes of the PPH03 stapler. The stapler is tightened slowly while applying traction on the purse-string. In women, posterior vaginal wall was ensured not to be incorporated in the purse string suture before tightening and firing the instrument. The instrument is left closed in this position for approximately 30 seconds before firing the stapler . After firing the stapler the PPH03 stapler is opened and stapler removed gently. The staple line is then examined for bleeding using the anuscope. They were followed up postoperatively regarding urinary retention, bleeding, anal pain and any other complications. Clinical evaluations including complete proctological examination ware routinely repeated at postoperative follow up on 5 to 7 days, 3 weeks and 2 months after surgery. After collection of required information, data were checked and processed manually, analyzed and edited by computer and simple statistical calculations were done by using percentage

\section{Result:}

Total 299 patients (M-210, F- 79) with median age of 37 years, with a diagnosis of primary haemorrhoidal disease 
underwent stapled haemorrhoidopexy. Around $89 \%$ of patient presented with painless per rectal bleeding. Bulks of the patients were treatment failure $2^{\text {nd }}$ and $3^{\text {rd }}$ degree haemorrhoids. $61 \%$ recovered uneventfully. Urgency of daefecation was the most frequent (19\%) early complication. Stenosis and recurrency were most common late complication.

\section{Table-1}

Patient's demography $(n=299)$

\begin{tabular}{lc} 
Variables & No. of patients (\%) \\
\hline Sex & M-210, F-79 \\
Age (years) & $37(21-80)$
\end{tabular}

Clinical features-

\begin{tabular}{lc} 
Per rectal bleeding & $266(88.9 \%)$ \\
Symptomatic prolapse & $191(63.87 \%)$ \\
Pruritus & $133(44.48 \%)$ \\
Discomfort & $77(25.75 \%)$ \\
Pain & $63(21.1 \%)$ \\
Anaemia requiring blood transfusion & $9(3.01 \%)$ \\
Degree of haemorrhoid- & \\
treatment failure $2^{\text {nd }}$ degree & $119(39.79 \%)$ \\
$3^{\text {rd }}$ degree & $150(50.16 \%)$ \\
$4^{\text {th }}$ degree & $31(11.03 \%)$ \\
\hline
\end{tabular}

Table-II

\begin{tabular}{lc}
\multicolumn{2}{c}{ Postoperative complications $(n=299)$} \\
Variables & No. of patients \\
\hline None & $182(61 \%)$ \\
Early & \\
$\quad$ Urgency of daefecation & $57(19 \%)$ \\
Urinary retension & $15(4.5 \%)$ \\
Aanal pain & $12(4.01 \%)$ \\
Reactionary haemorrhage & $09(3.01 \%)$ \\
Submucosal abscess & $02(0.66 \%)$ \\
Late & \\
Mild pain & $10(3.34 \%)$ \\
Flatus incontinence & $07(2.34 \%)$ \\
Stenosis & $09(3.01 \%)$ \\
Recurrent haemorrhoids & $09(3.01 \%)$ \\
Fissure & $02(0.66 \%)$ \\
\hline
\end{tabular}

\section{Discussion}

Haemorrhoidal disease is the disorder most frequently encountered in proctology. ${ }^{16}$ In recent times many techniques carrying various eponyms have been described. There are 2 basic varieties open and closed haemorrhoidectomy depending on whether or not the anorectal mucosa and perianal skin closed after the haemorrhoids have been excised and ligated, but the best one remain unanswered. Stapled haemorrhoidopexy is new and a very good technique to treat haemorrhoids with fewer complications and better patient satisfaction.

Complications related to the stapled haemorrhoidopexy (Longo) technique are external hemorroidal thrombosis, suture dehiscence, rectal perforation, submucosal hematoma, disabling persistent pain associated with a rectal syndrome, and sepsis. Very serious complications have been published in the literature. Certain authors attribute these complications to the learning curve for this surgery ${ }^{17,18}$. This cannot be considered in the present series since the serious complications were observed after procedures performed by surgeons experienced with the technique.

In our series urgency of daefecation is the most common early complication (19\%). Riaz AA et al found $15.2 \%$ had urgency of daefication. Cheetham ${ }^{19}$ reported that $31 \%$ had postoperative pain with defecation urgency lasting up to fifteen months.

Urinary retension was another troublesome but harmless complication. In our study it was $4.5 \%$ requiring catheterization. Sobardo et al found $3.9 \%$. There does not appear to be any clear explanation. We believe that the anesthesia could be involved.

Anal pain was another frequent complication in our series (early $4.01 \%$, late $3.34 \%$ ). In the literature, estimates range from $4 \%$ to $17.5 \%$. The pain can persist for several days or weeks or exceptionally months and often requires major analgesia ${ }^{17,18}$. The Longo technique is nevertheless advocated as being a less painful method ${ }^{20,21}$. Pain is very variable from one patient to another and is difficult to quantify. The intensity of pain also varies with the cultural context. On the first operative day after stapled hemorrhoidectomy, pain was scored 3 on a visual analog scale by 37 Italian patients 22 and 5 by 30 Finnish patients ${ }^{23}$. The duration of the painful period is also variable, ranging in our series from two days to six months. In a cohort of 16 patients, Cheetham ${ }^{17}$ reported that $31 \%$ had postoperative pain with defecation urgency lasting up to fifteen months. For certain authors ${ }^{17,24}$, the cause of pain can be explained by a low staple line too close to the sphincter. Pain can be avoided by placing the purse 
suture very high above the dentate line but with the risk of early relapse. A safety margin of 3 to $4 \mathrm{~cm}$ above the dentate line, recommended by Longo, is advocated by most authors $21,25,26$. For Cheetham, inclusion of muscle fibers in the mucosectomy could be a cause of persistent pain and defecation urgency

Hemorrhage is by far the earliest and most worrisome complication. For some authors, it is a problem especially during the early part of the learning curve ${ }^{27}$. In our series, hemorrhage was reported in $3.01 \%$ of patients. Incidence in the literature has been very variable from $0.6 \%$ to $10 \%$ 27, 28 . Many of our patients bleed during the operation or early in the postoperative period. Bleeding can also begin later and persist for several days ${ }^{26}$.

The most frequent cause of hemorrhage is arteriolar along the staple line. This can result from defective technique injuring the mucosa as observed in one of our patients. Topical treatment is usually required. Several methods have been proposed to achieve hemostasis. Foley catheter compression, surgical suture, meshing, and injection of epinephrine. Blood transfusion is required for some patients 21,28

Anal stricture developed in 3.01\% patients and was treated by anal dilatation. Three patients experienced defecation disorders (urgency) which resolved at three months. Incidence of postoperative stenosis was $8.8 \%$ and $1.6 \%$ in two retrospective series ${ }^{7,29}$. Most of the cases responded to anal dilatation ${ }^{7}$ while surgery was required in $1.4 \%$ of patients p $^{30}$

Fissures occur rarely $\left(0.2 \%\right.$ according to Slawik et al. ${ }^{31}$ and may be due to the trauma of a forceful insertion of the stapler into a tight anus in young males. in our study it was $0.6 \%$.In our study nine patients(3.01\%) developed recurrent hemorrhoid which were treated surgically in eight (Milligan-Morgan) and medically in one. Malika Oughriss et $\mathrm{al}^{7}$ found $3.2 \%$ recurrence rate.

\section{Conclusion:}

In this study, the stapled hemorrhoidopexy procedure was found safe. It was well tolerated by patients with minimal parenteral analgesic use and early discharge from hospital. The morbidity observed was also low in this procedure. Based on our experience, we suggest use of stapled hemorrhoidopexy as a valid option for symptomatic second degree and all third- and fourth-degree hemorrhoids.

\section{References:}

1. Varut Lohsiriwat Haemorrhoids: From basic pathophysiology to clinical management, World J Gastroenterol. 2012 May 7; 18(17): 2009-2017.

2. Holley CJ. History of haemorrhoidal surgery. South. Med. J. 1946; 39:536.
3. Madoff RD. Biblical management of anorectal disease. Presented at the Midwest Society of Colon and Rectal Surgeons meeting, March 1991, Breckenridge, CO.

4. Gordon PH, Nivatvongs S. Principles and Practice of Surgery for the Colon, Rectum, and Anus. 3rd ed. Informa Healthcare; 2007: Chapter 8 .

5. Acheson AG, Scholefield JH. Review Management of haemorrhoids;BMJ. 2008 Feb 16; 336(7640):380-3.

6. Longo, A. (1998) Treatment of haemorrhoidal disease by reduction of mucosa and haemorrhoidal prolapse with a circular suturing device: A new procedure. Proceedings of the 6th World Congress of Endoscopic Surgery, Rome, 3-6 June 1998, 777-784.

7. Oughriss M., Yver R. and Faucheron J.L. (2005) Complications of stapled haemorrhoidectomy: A French multicentric study. Gastroentérologie Clinique et Biologique, 29, 429-433. doi:GCB-04-2005-29-4-0399-8320-101019200513284 .

8. Maw, A., Eu, K.W. and Seow-Choen, F. (2002) Retroperitoneal sepsis complicating stapled haemorrhoidectomy: Report of a case and review of the literature. Diseases of the Colon \& Rectum, 45, 826-828.

9. Wong, L.Y., Jiang, J.K., Chang, S.C. and Lin, J.K. (2003) Rectal perforation: A life threatening complication of stapled haemorrhoidectomy: Report of a case. Diseases of the Colon \& Rectum, 46, 116-117. doi:10.1007/s10350-0046505-5.

10. Pescatori, M. (2003) PPH stapled haemorrhoidectomy-A cautionary note [comment]. Diseases of the Colon \& Rectum, 46, 131 .

11. Kuo RJ. Epidural morphine for post-haemorrhoidectomy analgesia. Dis. Colon Rectum, Letter to the Editor 1995; $38: 104$.

12. Hoff SD, Bailey HR, Butts DR, et al. Ambulatory surgical haemorrhoidectomy-A solution to postoperative urinary retention?. Dis. Colon Rectum 1994; 37:1242.

13. Petros JG, Bradley TM. Factors influencing postoperative urinary retention in patients undergoing surgery for benign anorectal disease. Am. J. Surg. 1990; 159:374.

14. Corman ML. Complications of hemorrhoid and fissure surgery. In: Ferrari BT, Ray JE, Gathright JB, ed. Complications of Colon and Rectal Surgery-Prevention and Management, Philadelphia: W.B. Saunders; 1985:91-100.

15. Milsom JW. Haemorrhoidal disease. In: Wexner SD, Beck DE, ed. Fundamentals of Anorectal Surgery, New York: McGraw-Hill.

16. Traore, A., Diake, I., Togo, A., et al. (2010) Haemorrhoidal Disease in the General Surgery Department of CHU Gabriel Toure. Médecine d'Afrique Noire, 57, 358-362.

17. Cheetham MJ, Mortensen NJ, Nystrom PO, Kamm MA, Phillips RK. Persistent pain and faecal urgency after stapled haemorrhoidectomy. Lancet 2000; 356: 730-3.

18. Herold A, Kirsch JJ. Pain after stapled haemorrhoidectomy. Lancet 2000; 356: 2187

19. Riaz AA,Singh A, Patel A, Ali A, Livingstone J, British J Med Practiotioners 2008; 1:23-7.

20. Mehigan BJ, Monson JR, Hartley JE. Stapling procedure for haemorrhoids versus Milligan-Morgan haemorrhoidectomy: randomized controlled trial. Lancet 2000; 355: 782-5. 
21. Hetzer FH, Demartines N, Handschin AE, Clavien PA. Stapled vs excision hemorrhoidectomy: long-term results of a prospective randomized trial. Arch Surg 2002; 137: 337-40.

22. Palimento D, Picchio M, Attanasio U, Lombardi A, Bambini C, Renda A. Stapled and open hemorrhoidectomy: randomized controlled trial of early results. World J Surg 2003; 27: 203-7.

23. Kairaluoma M, Nuorva K, Kellokumpu I. Day-case stapled (circular) vs. diathermy hemorrhoidectomy: a randomized, controlled trial evaluating surgical and functional outcome. Dis Colon Rectum 2003; 46: 93-9.

24. Ho YH, Tsang C, Tang CL, Nyam D, Eu KW, Seow-Choen F. Anal sphincter injuries from stapling instruments introduced transanally: randomized, controlled study with endoanal ultrasound and anorectal manometry. Dis Colon Rectum 2000; 43: $169-73$

25. Corman ML, Gravie JF, Hager T, Loudon MA, Mascagni D, Nystrom PO, et al. Stapled haemorrhoidopexy: a consensus position paper by an international working party indications, contra-indications and technique. Colorectal Dis 2003; 5 : 304-10.
26. Sutherland LM, Burchard AK, Matsuda K, Sweeney JL, Bokey EL, Childs PA, et al. A systematic review of stapled hemorrhoidectomy. Arch Surg 2002; 137: 1395-406.

27. Papillon M, Arnaud JP, Descottes B, Gravie JF, Huten X, De Manzini N. Le traitement de la maladie hémorroïdaire par la technique de Longo. Résultats préliminaires d'une étude prospective portant sur 94 cas. Chirurgie 1999; 124: 666-9.

28. Boccasanta P, Capretti PG, Venturi M, Cioffi U, De Simone M, Salamina G, et al. Randomised controlled trial between stapled circumferential mucosectomy and conventional circular hemorrhoidectomy in advanced hemorrhoids with external mucosal prolapse. Am J Surg 2001; 182: 64-8.

29. Ng KH, Seow-Choen F, Tang CL, Heah SM, Ooi SS (2004) Stapled hemorrhoidectomy. Our experience with more than 3000 cases. Colorect Dis 6[Suppl 2]:8

30. Ng KH, Ho KS, Ooi BS, Tang CL, Eu KW (2006) Experience of 3711 stapled haemorrhoidectomy operations. Br J Surg 93:226-230

31. Slawik S, Kenefick N, Greenslade GL, Dixon AR (2007) A prospective evaluation of stapled haemorrhoidopexy/rectal mucosectomy in the management of 3rd and 4th degree haemorrhoids. Colorectal Dis 9:352-356. 